\title{
Design of pH-sensitive polymer-modified liposomes for antigen delivery and their application in cancer immunotherapy
}

\author{
Eiji Yuba
}

The accurate delivery of antigens into the cytosol of antigen-presenting cells, such as dendritic cells, is crucially important for the induction of cellular immunity in efficient cancer immunotherapy. To date, the cytoplasmic delivery of antigens has been achieved with various delivery systems. Among them, pH-sensitive liposomes are a promising option because of their $\mathrm{pH}$-responsive membrane disruption or fusion abilities, which cause the encapsulated antigen to be transferred into the cytosol. Recently, liposomes modified with $\mathrm{pH}$-sensitive polymers have been used as highly effective antigen delivery systems. The control of the pH-responsive fusion ability and the intracellular distribution of antigens, the induction of humoral or cellular immunity in vivo, the induction of protective immunity against pathogens, and the treatment of tumor-bearing mice have been achieved using these liposomes. The design and function of these $\mathrm{pH}$-sensitive polymer-modified liposomes are outlined in this review.

Polymer Journal (2016) 48, 761-771; doi:10.1038/pj.2016.31; published online 23 March 2016

\section{INTRODUCTION}

Cancer immunotherapy, which activates the patient's own immune system to fight cancer or removes immunosuppression in tumor microenvironments, has gained much attention as an alternative to standard cancer therapies. ${ }^{1-3}$ To date, various cancer immunotherapy methods have been studied, such as adoptive T-cell transfer therapy, dendritic cell (DC) vaccines and immune checkpoint inhibitors. ${ }^{1-7}$ Among them, the activation of the immune system against cancer via DCs is an attractive treatment because of its selectivity and safety. ${ }^{4}$ In 2010, Sipuleucel-T (Provenge; Dendreon Corp.), a DC vaccine against prostate adenocarcinoma, was approved by the US FDA., Since then, DC cancer vaccines have received much attention from numerous researchers.

As antigen-presenting cells, DCs have a crucial role in starting and activating the immune system. ${ }^{8,9}$ DCs recognize the tumor antigens and present them to $\mathrm{T}$ cells. The activated $\mathrm{T}$ cells or $\mathrm{B}$ cells subsequently attack the tumor directly or via antibodies. Two major pathways exist for antigen presentation by DCs (Figure 1). In the first pathway, the exogenous antigen is degraded via the endosome pathway and is loaded onto major histocompatibility complex (MHC) class II molecules, thus inducing humoral immunity. In the second pathway, the endogenous antigen is degraded in proteasomes and is loaded onto MHC class I molecules, thereby inducing cellular immunity. To achieve effective cancer immunotherapy, the induction of cellular immunity is important. To induce cellular immunity, the transfer of the exogenous antigen to the cytosol and the induction of MHC class I-mediated presentation, which is termed 'crosspresentation', are necessary (Figure 1). Therefore, an efficient cytoplasmic delivery system of exogenous antigens is necessary to induce 'cross-presentation' and to achieve effective cancer immunotherapy.

To date, various delivery systems have been studied for the cytoplasmic delivery of antigens. ${ }^{10-26}$ Among them, lipid-based delivery systems, such as liposomes, are attractive because liposomes can achieve cytoplasmic delivery by exploiting biological functions, such as membrane fusion. ${ }^{10-13,23-26}$ Two strategies are used for cytoplasmic delivery. One strategy is the direct delivery of exogenous antigens into the cytosol, which can be achieved by methods such as direct fusion of Sendai virus fusion protein-incorporated liposomes or a combination of bubble liposomes with the cellular membrane through ultrasound. ${ }^{10,11,27}$ Another strategy of cytoplasmic delivery is the promotion of the endosomal escape of an antigen, which can be achieved with influenza virus fusion protein-introduced liposomes (virosome) or $\mathrm{pH}$-sensitive liposomes. ${ }^{12,13,23-25,28}$ However, viral protein-based liposomes may cause unfavorable immune responses derived from their viral components. Therefore, the use of $\mathrm{pH}$-sensitive liposomes prepared from synthetic molecules is desirable.

Two methods are used for the preparation of $\mathrm{pH}$-sensitive liposomes: the inclusion of $\mathrm{pH}$-sensitive amphiphiles and the modification of $\mathrm{pH}$-sensitive polymers into stable liposomes. In the case of $\mathrm{pH}$-sensitive amphiphiles, nonbilayer-forming lipids such as dioleoylphosphatidylethanolamine are used as a lipid component. $^{24,25,29}$ Therefore, it is difficult to combine the stability 
of the liposome with high sensitivity. However, poly(carboxylic acid)s such as poly(acrylic acid) derivatives have been used as typical $\mathrm{pH}$-sensitive polymers to prepare $\mathrm{pH}$-sensitive polymer-modified

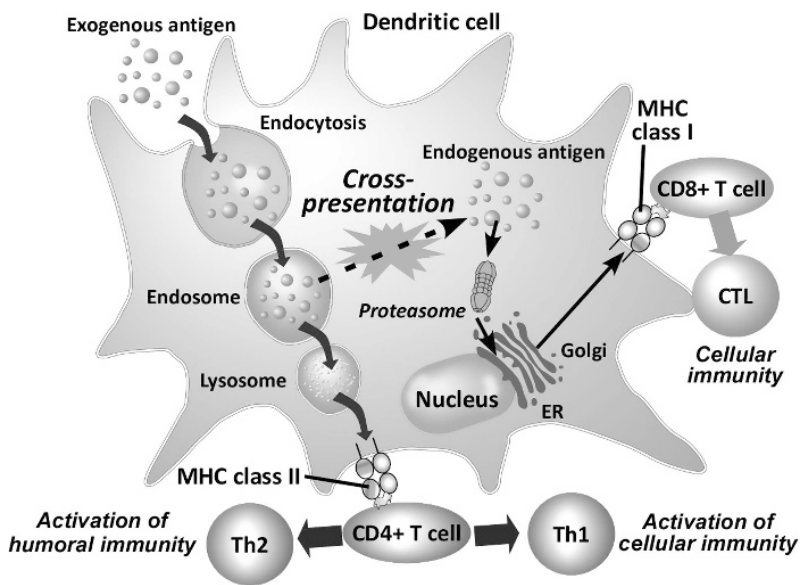

Figure 1 Antigen-presenting pathway of a dendritic cell. Cellular immunity is generally induced via the MHC class I presentation of endogenous antigens. Part of exogenous antigens escape from the endosome and are presented by MHC class I molecules ('cross-presentation'). To promote the cross-presentation process, $\mathrm{pH}$-sensitive molecules have been studied for the destabilization of endosomal membranes or induction of fusion with endosomal membranes. A full color version of this figure is available at Polymer Journal online. liposomes (Figures 2a and b). ${ }^{30-32}$ These polymers form mixed micelles with lipids at acidic $\mathrm{pH}$, which causes liposomal membrane lysis. ${ }^{33-35}$ The hydrophobicity of the poly(acrylic acid) derivatives strongly affects their membrane-disrupting capability. ${ }^{36}$ Notably, poly (propyl acrylic acid) has a greater ability to induce membrane disruption, responding to a weakly acidic $\mathrm{pH}$, than poly(ethyl acrylic acid). ${ }^{36,37}$ Poly(propyl acrylic acid) has been applied to antigen delivery by direct conjugation to antigenic proteins. ${ }^{38,39}$ These antigen-polymer conjugates or conjugate-based micelles induce 'cross-presentation' in vitro and cellular immune responses in vivo. ${ }^{38-41}$ The endosomal membrane-lysis activity derived from poly(propyl acrylic acid) might enhance the delivery of antigenic proteins into the cytosol of DCs, thereby causing the induction of efficient cross-presentation.

Our group has developed $\mathrm{pH}$-sensitive polymers of another type using poly(glycidol)s, which have a poly(ethylene glycol)-like main chain structure. ${ }^{42,43}$ Dicarboxylic acid anhydrides, such as succinic anhydride, have been reacted with the hydroxyl groups of the poly(glycidol)s, resulting in succinylated poly(glycidol) (SucPG, Figure 2c). ${ }^{42,43}$ Long alkyl chains have also been introduced into some of the carboxyl groups (typically approximately $10 \%$ for hydroxyl groups) to fix the polymer onto the liposome membrane. SucPG-modified egg yolk phosphatidylcholine liposomes exhibit content (calcein) release under acidic $\mathrm{pH}$ and have been observed to deliver calcein to the cytosol of CV1 cells. ${ }^{43}$ Analyses of the intracellular fusion behavior of liposomes based on fluorescence resonance energy transfer have revealed that SucPG-modified<smiles>CCCCCCCCCCCNC(=O)CC(C)CC(C)=O</smiles>

f<smiles>CCCCCCCCCCCCCCCCCCC(=O)OCC(COP(=O)(O)OCCNC(=O)CCCC(=O)OCC(CO)[18O]C([18OH])[18F])OC(=O)CCCCCCCCCCCCCCC</smiles><smiles>CC(=O)C1CCCCC1C(=O)O</smiles>

Figure 2 Structures of pH-sensitive polymers. (a) poly(2-ethylacrylic acid), (b) poly(2-propylacrylic acid), (c) SucPG, (d) MGluPG, (e) MGlu-HPG with degree of polymerization (DP) of 40, (f) MGluPG-PE and CHexPG-PE, and (g) 3-methylglutarylated dextran (MGlu-Dex). 


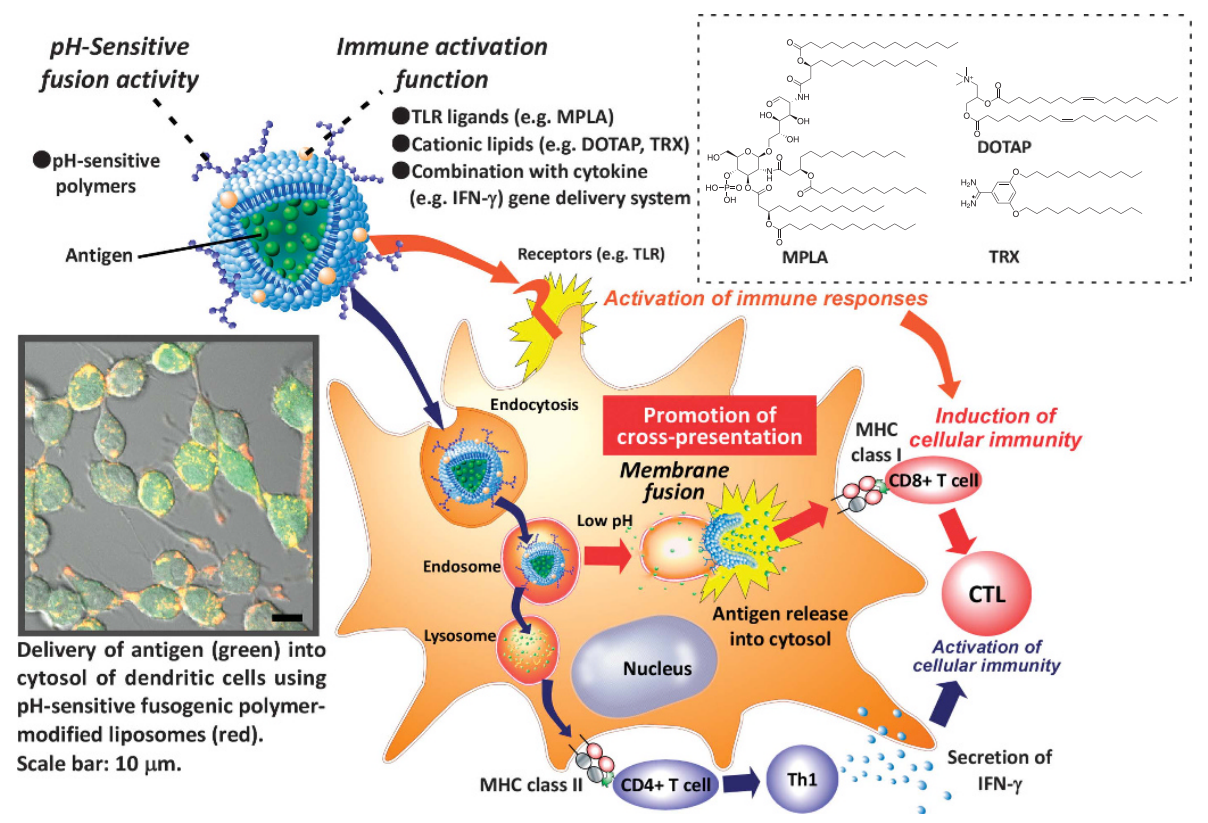

Figure 3 Design of liposomal vaccine with $\mathrm{pH}$-sensitive activity and immune activation function. The antigen-loaded liposomes were modified with $\mathrm{pH}$-sensitive polymers and adjuvant molecules/systems (such as TLR ligands, cationic lipids or cytokine (IFN- $\gamma$ ) gene delivery systems). After internalization via endocytosis, the liposomes induce fusion with endosomal membranes, responding to the acidic $\mathrm{pH}$ inside of the endosomes, thus causing the transfer of most of the antigen into the cytosol, as shown in the fluorescence microscopic image. As a result, cross-presentation is promoted, leading to the induction of cellular immunity. In addition, the dendritic cells are activated by stimulation via the interaction between the adjuvant molecules and receptors, which causes the activation of immune responses. Otherwise, IFN- $\gamma$ produced by Th1 cells or IFN- $\gamma$ gene-transfected dendritic cells also activates cellular immunity. The microscopy image in the figure shows DC2.4 cells treated with fluorescein isothiocyanate (FITC)-OVA-loaded MGlu-HPG liposomes labeled with Rhodamine-PE. The green fluorescence shows the location of FITC-OVA, and the red fluorescence shows the location of the liposomes.

liposomes show membrane fusion ability under acidic $\mathrm{pH}$, unlike the poly(acrylic acid) derivatives, which cause membrane lysis. ${ }^{43}$ The poly (ethylene glycol)-like main chain structure of SucPG might induce 'mild' insertion of the polymer chain into the liposome membrane under acidic conditions, resulting in the induction of membrane defects and causing membrane fusion. ${ }^{43}$ In contrast, the poly(acrylic acid) derivatives, which have a vinyl main-chain structure, might be inserted deeply into the lipid bilayer under the same conditions, thereby causing the comprehensive destabilization of the lipid membrane. ${ }^{32}$

On the basis of the intracellular delivery performance of the carboxylated poly(glycidol)s, carboxylated poly(glycidol)-modified liposomes have been applied to antigen delivery into the cytosol of DCs to induce cross-presentation and cellular immunity (Figure 3). This review presents a discussion on the effects of the carboxylated poly(glycidol) structure on the performance of the intracellular delivery of antigens and the induction of cellular immune responses against cancer or an infectious disease model. Carboxylated dextrans have also been developed as safer $\mathrm{pH}$-sensitive polymers. Their capability for use as a cancer vaccine has been evaluated. To induce stronger immune responses, adjuvant (immune-activating) molecules or functionalities have been introduced into the $\mathrm{pH}$-sensitive polymermodified liposomes and their performance was evaluated.

\section{DESIGN OF pH-SENSITIVE POLYMERS FOR CYTOPLASMIC DELIVERY}

When poly(carboxylic acid)s interact with a lipid membrane, the main mechanisms for lipid membrane destabilization are hydrophobic interactions of the poly(carboxylic acid) main chain with the hydrophobic domain of the lipid bilayer and hydrogen bonding between the carboxyl groups of the polymer and the phosphate groups on the surface of lipid membrane. ${ }^{32}$ Therefore, the structures of the carboxylated poly(glycidol)s might strongly affect their fusogenic performance. Hence, poly(glycidol)s with various sidechain structures have been prepared. ${ }^{44}$ With increasing hydrophobicity of the side-chain structures, the membrane-disruption properties of these polymers at acidic $\mathrm{pH}$ increases. ${ }^{44}$ Notably, 3-methylglutarylated poly(glycidol) (MGluPG, Figure 2d) exhibits strong membrane fusion activity at the weakly acidic $\mathrm{pH}$ corresponding to endosomal $\mathrm{pH}$ regions, which is suitable for the performance of a $\mathrm{pH}$-responsive intracellular delivery system. Furthermore, MGluPG-modified liposomes can achieve cytoplasmic delivery of calcein into HeLa cells at faster rates than those of SucPG-modified liposomes. ${ }^{44}$

SucPG-modified and MGluPG-modified liposomes have been applied to the delivery of antigens into DCs. ${ }^{45}$ Ovalbumin (OVA) has been encapsulated as a model antigenic protein in liposomes composed of egg yolk phosphatidylcholine and dioleoylphosphatidylethanolamine. The OVA-loaded liposomes have been added to DC2.4 cells, a murine DC line. Compared with polymer-unmodified liposomes, both the SucPG-modified and MGluPG-modified liposomes show a five-fold increase in cellular association (Figure 4a). ${ }^{45}$ DCs and macrophages are known to engulf microorganisms or apoptotic cells having anionic components via scavenger receptors. ${ }^{46,47}$ Given that the SucPG-modified and MGluPG-modified liposomes have negatively charged surfaces because of the carboxyl groups in their polymer side chains, these liposomes are likely to be taken up by the DC2.4 cells via interactions with scavenger receptors. In fact, the addition of dextran sulfate, an inhibitor of the interactions between negatively charged compounds and scavenger receptors, strongly suppresses the association of the SucPG-modified liposome-based nanoparticles to the DC2.4 cells. ${ }^{48}$ In general, negatively charged surfaces suppress the interactions between cells and nanoparticles. ${ }^{49,50}$ Therefore, these 


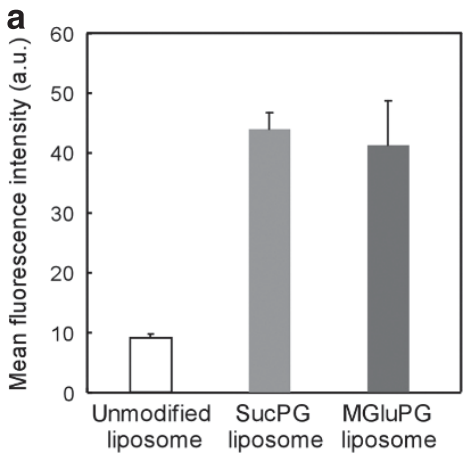

b

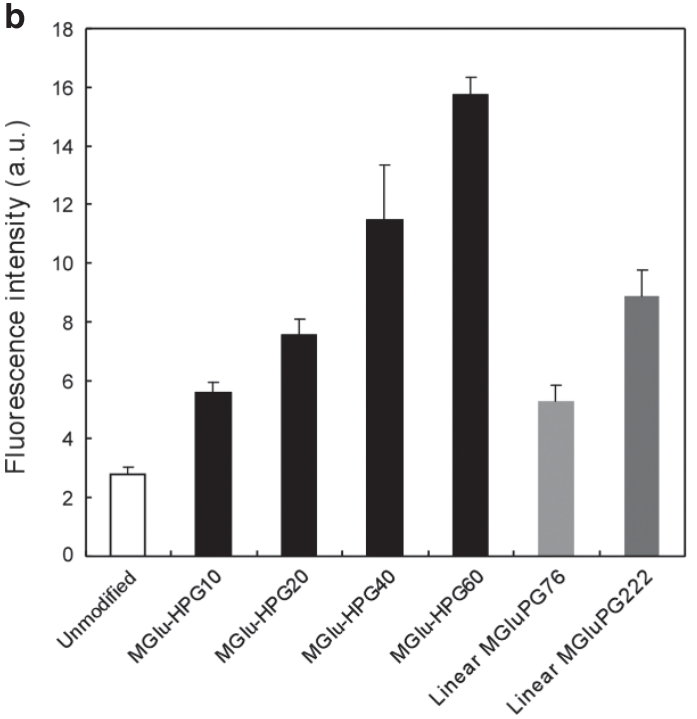

C

Liposome modified with
MGlu-HPG with high DP Liposome
modified with
MGlu-HPG
with low DP

Liposome
modified with
MGlu-HPG
with low DP

Liposome
modified with
MGlu-HPG
with low DP

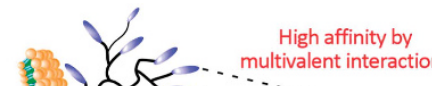
High affinity by
multivalent interaction
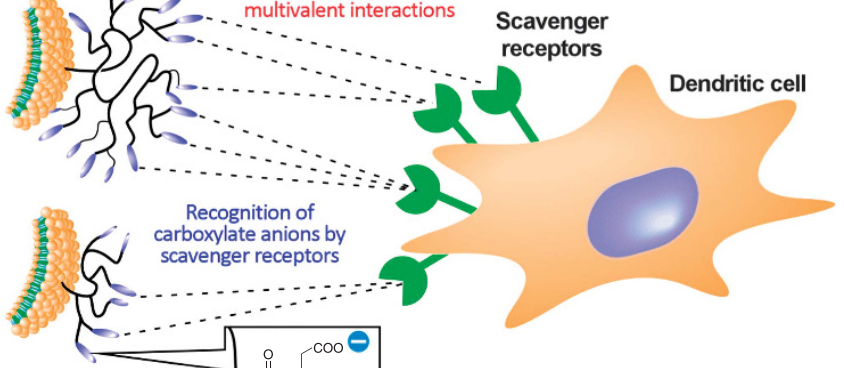

$\cos \theta$
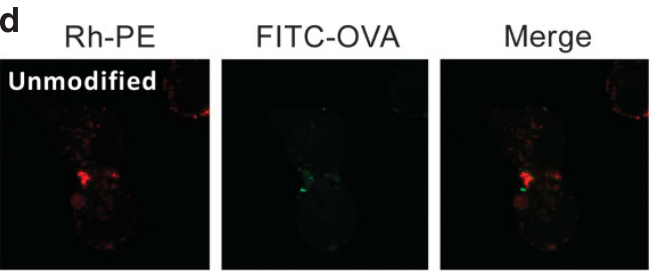

MGlu-HPG60
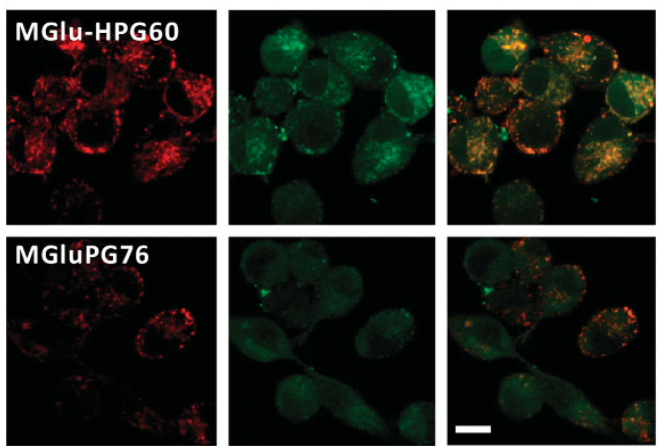

Figure $4(\mathbf{a}, \mathbf{b})$ Mean fluorescence intensity of DC2.4 cells treated with liposomes modified with SucPG, MGluPGs and MGlu-HPGs having various degrees of polymerization (DP). Cellular association of the liposomes to DC2.4 cells was promoted by carboxylated polymer modification (a) and increased with increasing DP of MGlu-HPG (b). (c) Schematic illustration for the interaction of MGlu-HPG-modified liposomes with DCs. (d) Confocal laser scanning microscopy (CLSM) images of DC2.4 cells treated with Rh-PE-labeled and fluorescein isothiocyanate (FITC)-OVA-loaded liposomes modified with MGlu-HPG60, MGluPG76 or without polymers. The intracellular localization of Rh-PE (red) and FITC-OVA (green) were observed using a CLSM. The scale bar represents $10 \mu \mathrm{m}$. Partially reproduced from Yuba et al. ${ }^{45,53}$ with permission. Copyright (2010 and 2011) Elsevier.

pH-sensitive polymer-modified liposomes are preferentially taken up by macrophages or DCs, compared with other cells in the body with no scavenger receptors. These properties of carboxylated polymermodified liposomes are particularly beneficial because they achieve selective association of the liposomes to antigen-presenting cells in the body. According to the analyses of the intracellular distribution of the liposomes and fluorescein isothiocyanate-labeled OVA, the OVA molecules are delivered into the cytosol of DC2.4 cells by the MGluPG-modified liposomes, which show stronger fusion activity than that of the SucPG-modified liposomes. ${ }^{45}$

Given the membrane fusion mechanism of viral fusogenic proteins, the three-dimensional structures of these proteins might have an important role in generating defects in lipid membranes and subsequently inducing membrane fusion. ${ }^{51,52}$ Therefore, fusogenic polymers having three-dimensional structures might be expected to show a stronger fusion activity. For that reason, hyperbranched poly (glycidol)s (HPGs) with various degrees of polymerization have been used as the main chain of a pH-sensitive polymer (Figure 2e). ${ }^{53}$ MGlu-HPG, an analogous polymer of linear MGluPG, forms more hydrophobic domains at a weakly acidic $\mathrm{pH}$ than MGluPG with the same degree of polymerization. ${ }^{53}$ Reflecting this result, MGlu-HPG shows a higher membrane disruption ability at a weakly acidic $\mathrm{pH}$ than that of MGluPG. ${ }^{53}$ These results indicate that the hyperbranched polymer backbone might be more beneficial for the induction of membrane fusion than the linear polymer backbone. In addition, cellular association increases concomitantly with increasing degree of polymerization of MGlu-HPG (Figure 4b), indicating that bulkier polymer-modified liposomes might interact with scavenger receptors on the DCs through multivalent interactions because of their threedimensional structures (Figure 4c). ${ }^{53}$ After their internalization into the cells, the MGlu-HPG-modified liposomes show intracellular fusion activity and deliver OVA into the cytosol of DC2.4 cells more efficiently than the MGluPG-modified liposomes (Figure 4d). ${ }^{53}$

As another type of $\mathrm{pH}$-sensitive polymer, $\mathrm{pH}$-sensitive polymerlipids have been prepared for the $\mathrm{pH}$-sensitization of liposomes. ${ }^{54}$ Compared with random anchor polymers, polymers having a phospholipid moiety can introduce the $\mathrm{pH}$-sensitive polymer into the liposome without disruption of the lipid membrane structure. Polymer-lipids of two types have been synthesized: MGluPG-PE and CHexPG-PE, which are distearyl phosphatidylethanolamines with 3-methylglutarylated or 2-carboxycyclohexane-1-carboxylated poly (glycidol) groups, respectively (Figure 2f). ${ }^{54}$ The polymer-lipidincorporated liposomes show content release in specific $\mathrm{pH}$ regions depending on their side-chain structures and polymer-lipid contents. ${ }^{54}$ 

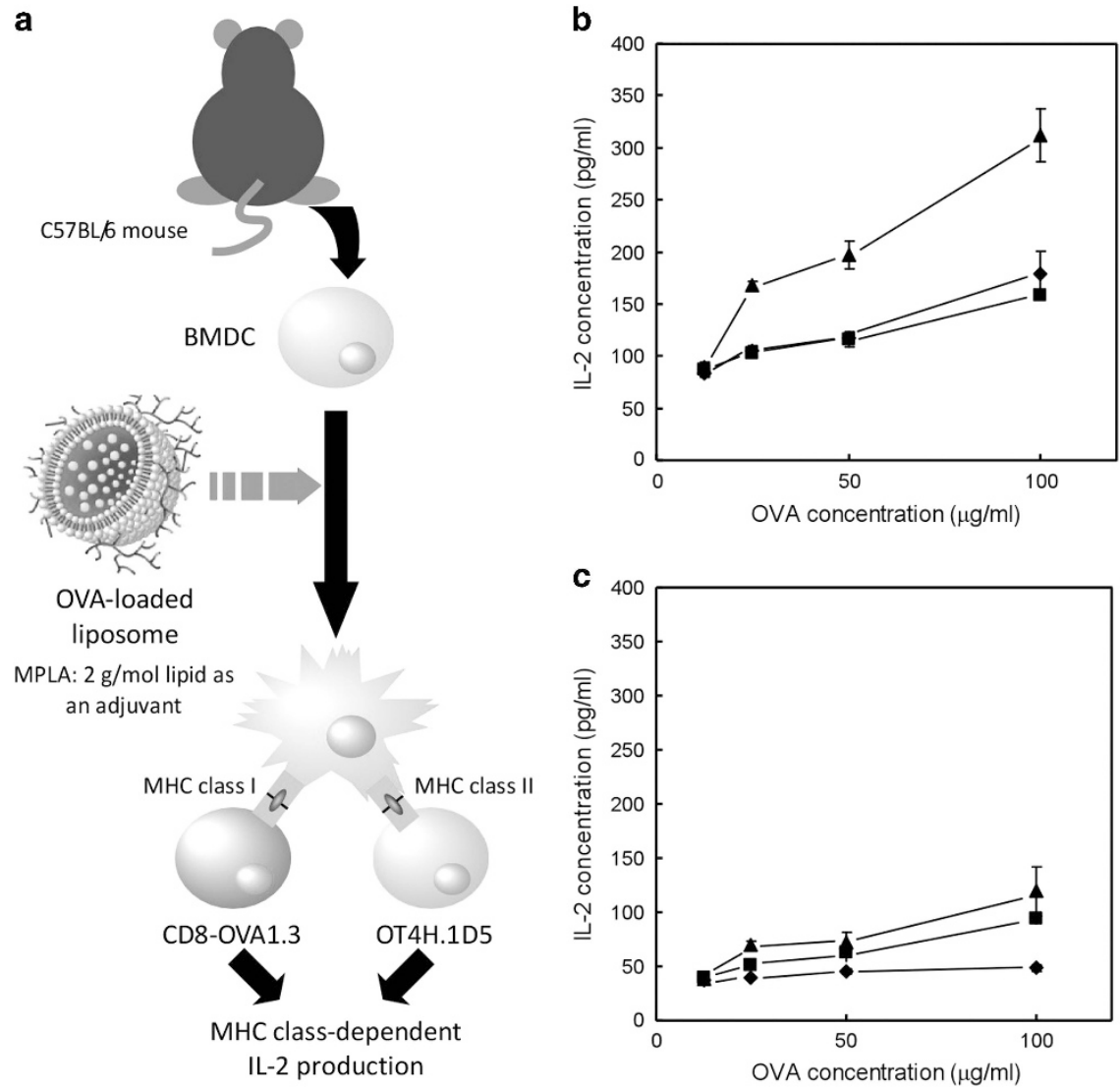

Figure 5 Presentation of OVA-derived epitope peptides via MHC molecules in bone marrow-derived DCs (BMDCs). (a) Schematic illustration of the experimental procedure. BMDCs were incubated with free OVA (diamonds), OVA-loaded MGluPG-modified liposomes (triangles) and unmodified liposomes (squares) at varying OVA concentrations for $3 \mathrm{~h}$. Concentrations of IL-2 in the medium after co-culture of OVA-treated BMDCs with (b) CD8-OVA1.3 (specific for $\mathrm{OVA}_{257-264} / \mathrm{H}-2 \mathrm{~K}^{\mathrm{b}}$ complex, MHC class I pathway) and (c) OT4H.1D5 (specific for OVA $265-277 / \mathrm{l}-\mathrm{A}^{\mathrm{b}}$ complex, MHC class II pathway) cells for $24 \mathrm{~h}$ as a function of OVA concentration during the BMDCs treatment are shown. Partially reproduced from Yuba et al. ${ }^{45}$ with permission. Copyright (2010) Elsevier. A full color version of this figure is available at Polymer Journal online.

In addition, polymer-lipid liposomes show high cellular association with DC2.4 cells and deliver their contents into the cytosol of the cells. ${ }^{54}$ Notably, CHexPG-PE exhibits excellent delivery performance, even at lower polymer-lipid contents. ${ }^{54}$ The hydrophobicity of the side chains in $\mathrm{pH}$-sensitive polymers strongly affects their $\mathrm{pH}$-sensitivity and intracellular delivery performance.

\section{APPLICATION OF pH-SENSITIVE POLYMER-MODIFIED LIPOSOMES TO ANTIGEN CARRIERS}

The $\mathrm{pH}$-sensitive polymer-modified liposomes achieve cytoplasmic delivery of their contents into DCs. The cytoplasmic delivery of antigens into DCs induces MHC class I-mediated presentation (cross-presentation), resulting in the induction of cellular immunity (Figure 1). Therefore, the application of these liposomes to the induction of antigen-specific immune responses has been investigated.

The antigen presentation pathway has been evaluated using $\mathrm{T}$ cells (CD8-OVA1.3 cells or OT4H.1D5 cells), which recognize MHC class I- or class II-dependent antigen presentation, respectively (Figure 5a). ${ }^{55,56}$ OVA has been used as a model antigen, and monophosphoryl lipid A has been incorporated into the liposomes as an adjuvant. ${ }^{57}$ Bone marrow-derived DCs treated with the MGluPG-modified liposomes show higher levels of antigen presentation than those of the unmodified liposome-treated bone marrowderived DCs (Figure 5). ${ }^{45,58}$ Notably, the MGluPG-modified liposomes induce MHC class I-mediated antigen presentation more efficiently than the unmodified liposomes (Figure 5b). These results indicate that the higher cellular association of the liposomes and the efficient cytoplasmic delivery of the antigen by the MGluPG-modified liposomes promotes MHC class I-mediated antigen presentation.

OVA-loaded liposomes have also been administered nasally to mice, and the OVA-specific antibody production and the induction of OVA-specific cytotoxic T lymphocytes (CTLs) in the spleen have been evaluated. ${ }^{45,59-61}$ Mucosal surfaces are the main route for the entry of pathogens into the body. The induction of both mucosal and systemic immunity against pathogens is important to guard against pathogen infection. ${ }^{62-66}$ The nasal administration of $\mathrm{pH}$-sensitive polymermodified liposomes to mice induces the production of OVA-specific antibodies in the serum and intestines. ${ }^{60,61}$ In addition, the splenocytes of the mice produce Th1 cytokines (IFN- $\gamma$ ) and induce cytotoxic activity against the OVA-expressing cells (E.G7-OVA cells) but not against the cells without OVA expression (EL4 cells). ${ }^{45,61}$ These results indicate that $\mathrm{pH}$-sensitive polymer-modified liposomes induce protective immunity against pathogens invading the mucosal tissues. To evaluate the usefulness of polymer-modified liposomes as mucosal vaccines, Salmonella enteritidis antigen-containing liposomes modified with MGluPG have been administered to the eyes of chickens for control of Salmonella infection. ${ }^{61}$ Intraocular immunization with the S. enteritidis antigen-containing MGluPG-modified liposomes induces antigen-specific IgG and IgA production in the serum and intestines. Importantly, the MGluPG-modified liposomes induce higher IgA 

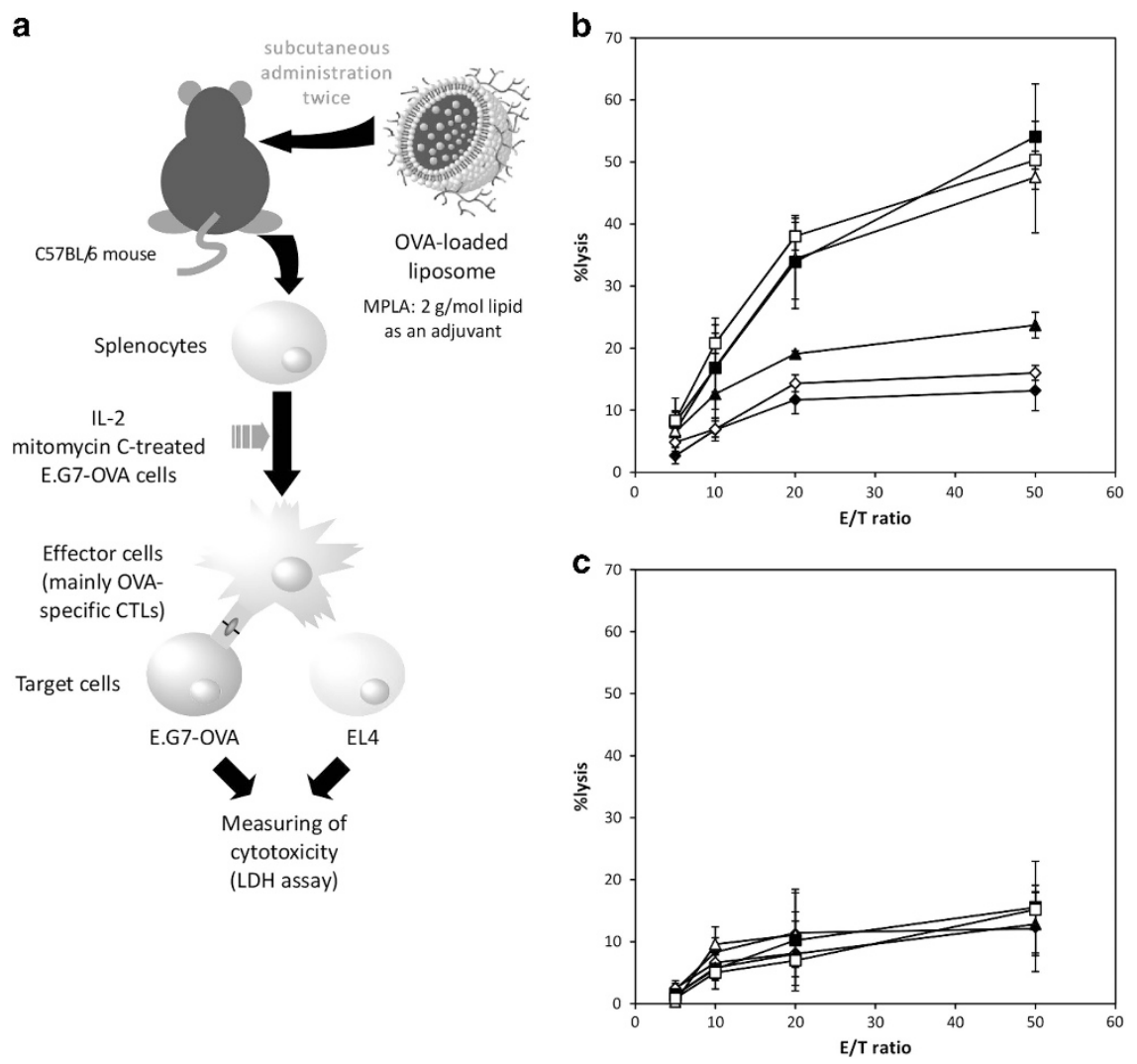

Figure 6 OVA-specific CTL induction in the spleen 7 days after subcutaneous immunization with phosphate-buffered saline (closed diamonds), OVA solution (open diamonds), unmodified liposomes (closed triangles), MGluPG-modified liposomes (open triangles), MGlu-HPG-modified liposomes (closed squares) and Complete Freund's adjuvant (CFA, open squares). (a) Schematic illustration of experimental procedure. Cytotoxic activity was measured by a lactate dehydrogenase (LDH) assay at various effector cell/target cell (E/T) ratios. The amount of OVA administered was $100 \mu$ g per mouse. E.G7-OVA cells (b) and EL4 cells (c) were used as the target cells. Partially reproduced from Yuba et al. ${ }^{58}$ with permission. Copyright (2013) Elsevier. A full color version of this figure is available at Polymer Journal online.

production than does the commercial S. enteritidis vaccine. ${ }^{61}$ Fewer bacteria in fecal waste and the cecum have been found in liposomeimmunized chickens than in unimmunized controls. ${ }^{61}$ These results indicate that $\mathrm{pH}$-sensitive polymer-modified liposomes induced antigen-specific antibodies in mucosal tissues and Th1-polarized immune responses in vivo through efficient cross-presentation of antigens, thus providing efficient protection against pathogens.

\section{APPLICATION OF pH-SENSITIVE POLYMER-MODIFIED LIPOSOMES TO CANCER IMMUNOTHERAPY}

The feasibility of use of pH-sensitive polymer-modified liposomes as antigen delivery carriers in cancer immunotherapy has been investigated. The subcutaneous administration of these liposomes to mice induces cellular immune responses in the spleen, as observed after nasal administration of the same liposomes (Figure 6). ${ }^{58}$ The administration of the MGlu-HPG-modified and MGluPG-modified liposomes generates antigen-specific CTLs with the same efficiency regardless of differences in their antigen delivery efficiency in vitro (Figures $4 \mathrm{~b}$ and $6 \mathrm{~b}$ ). Both liposomes are probably sufficiently taken up by antigen-presenting cells in the body to induce strong cellular immunity. Consequently, protective immunity against the OVAexpressing E.G7-OVA cells is induced, considerably improving mice survival. ${ }^{58}$ An example of the therapeutic effects of these liposomes for tumor-bearing mice is depicted in Figure 7. In the experiment, E.G7-OVA cells were injected into the mice. Then, the change in tumor volumes was measured 7 days after the OVA-loaded liposomes were administered to these mice. The results show that administration of the MGluPG-modified or MGlu-HPG-modified liposomes suppresses tumor growth and regresses the tumor volumes to a significant degree (Figure 7a). In fact, $50-75 \%$ of the mice were cured completely (Figure 7b). ${ }^{58}$ These results indicate that the strong cellular immunity induced by the $\mathrm{pH}$-sensitive polymer-modified liposomes efficiently killed the OVA-expressing tumor cells, leading to tumor rejection and regression. According to the results of the cytotoxic activity of splenocytes against EL4 cells (OVA-non-expressing cells), approximately 10\% non-specific cytotoxicity was observed (Figure 6c). However, the OVA-loaded MGluPG-modified liposomes showed no antitumor effects against EL4-tumor-bearing mice, as previously reported. ${ }^{67}$ These results clearly indicate that non-specific cytotoxic activity was not sufficient to obtain antitumor effects, and the E.G7-OVA tumor cells were killed by the OVA-specific CTLs induced by the $\mathrm{pH}$-sensitive polymer-modified liposomes.

As described above, the membrane-disrupting capabilities of $\mathrm{pH}$-sensitive polymers are influenced by the hydrophobicity of the introduced $\mathrm{pH}$-sensitive moieties. For example, CHexPG-PE liposomes show sharp destabilization at a very weakly acidic $\mathrm{pH}$ of approximately 6.5-7.0, whereas MGluPG-PE liposomes exhibit destabilization at a $\mathrm{pH}$ of approximately $5 .{ }^{54}$ When these polymerlipid-incorporated liposomes containing OVA are administered subcutaneously to mice, antigen-specific cellular immunity is induced in the mice for both cases. ${ }^{54}$ However, immunization with the CHexPGPE liposomes induces stronger therapeutic effects than those with the 

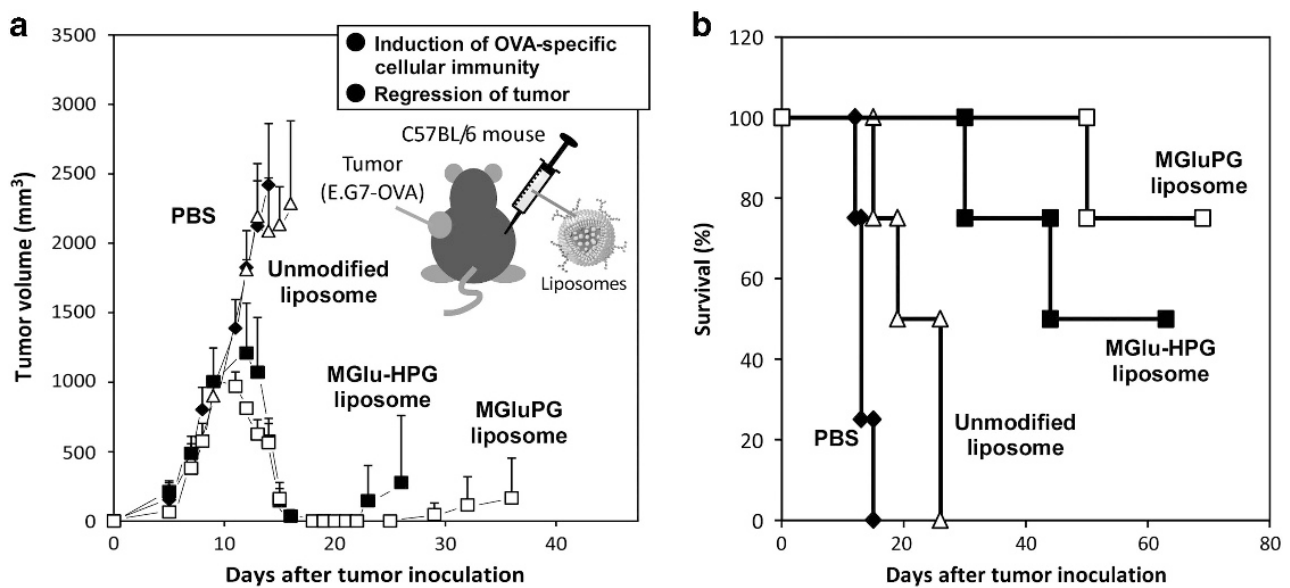

Figure 7 Antigen-specific antitumor effect induced by subcutaneous administration of pH-sensitive polymer-modified liposomes. The E.G7-OVA cells were subcutaneously inoculated into the left backs of C57BL/6 mice, and then liposomes with or without pH-sensitive polymers containing $100 \mu \mathrm{g}$ of $\mathrm{OVA}$ were subcutaneously administered into the right backs of the mice on days 7 and 14. Mice immunized with phosphate-buffered saline are shown as controls. All the treated groups contained four mice. (a) Change in tumor volume and (b) survival curves of mice are shown. Partially reproduced from Yuba et al. ${ }^{58}$ with permission. Copyright (2013) Elsevier. A full color version of this figure is available at Polymer Journal online.

MGluPG-PE liposomes. ${ }^{54}$ In fact, we have observed complete rejection of the OVA-expressing E.G7-OVA cells and marked regression of the E.G7-OVA tumors in the mice treated with the CHexPG-PE liposomes. ${ }^{54}$ The strong and highly sensitive response of the liposomes to a very weakly acidic $\mathrm{pH}$ might promote the efficient induction of antigen-specific cellular immunity.

From the viewpoint of clinical applications, safer materials are desirable for the preparation of liposomes. Therefore, instead of a synthetic polymer (poly(glycidol)), the biopolymer-based $\mathrm{pH}$-sensitive polymer, 3-methylglutarylated dextran (Figure 2g) has been developed. ${ }^{68}$ 3-Methylglutarylated dextran-modified liposomes efficiently deliver antigens into the cytosol of DC2.4 cells and induce antitumor effects against tumor-bearing mice. ${ }^{68}$ The effects of the MGlu group content of the polymer and molecular weights of dextran on their immune-inducement effects have also been evaluated. Dextran with intermediate amounts of MGlu groups (MGlu56-Dex) shows the strongest antitumor effects, and the molecular weights of dextran do not affect their immune-inducement effects. ${ }^{68}$

\section{TOWARD A MORE EFFECTIVE ANTIGEN DELIVERY SYSTEM}

Delivery systems require not only cytoplasmic delivery functions but also activation functions of the DCs to produce more effective antigen delivery systems. Hence, the combination of activation molecules or systems (adjuvant molecules or systems) with $\mathrm{pH}$-sensitive polymermodified liposomes to induce more effective cancer immunity has been evaluated (Figure 3).

To date, various adjuvant molecules have been introduced into antigen delivery systems. Typically, toll-like receptor (TLR) ligands, molecules that are derived from bacterial or viral components and are recognized by TLRs expressed in immune-competent cells, are used as adjuvant molecules. ${ }^{69-71}$ For example, the incorporation of CpG-DNA, poly(I:C) and monophosphoryl lipid A, which are known, respectively, as TLR9, TLR7 and TLR4 ligands, enhances the immuneinducement effects of antigen delivery systems. In our studies, we have found that the inclusion of monophosphoryl lipid A in MGlu-HPGmodified liposomes as a part of the lipid membrane component strongly promotes their antitumor immunity compared with that of the liposomes without monophosphoryl lipid A. ${ }^{72}$ However, considering that the TLR ligands are obtained from bacteria or viruses, these molecules might display variation in biological activity, and thus there is a possibility of unexpected side effects originating from their structural variety and molecular purity. Therefore, for practical use, other adjuvants must be considered for the modification of the liposome-based vaccines. One candidate adjuvant might be cationic lipids, which are known to have adjuvant function by activation of intracellular signaling via the interaction with various membrane proteins. $^{73}$ 1,2-Dioleoyl-3-dimethylammoniumpropane is the most studied cationic lipid that might be used as an adjuvant molecule. ${ }^{73-76}$ 1,2-Dioleoyl-3-dimethylammoniumpropane is recognized by the $G$ protein-coupled receptors on the cellular membranes of DCs, and it activates MAP kinases, which induce the upregulation of the co-stimulatory molecules CD80 or CD86 on DCs. ${ }^{73}$ Reactive oxygen species generated by cationic lipids or cationic liposomes also have a role in inducing multiple signaling pathways for the production of cytokines and upregulation of co-stimulatory molecules. ${ }^{77}$ Furthermore, cationic lipids with an amidine group are known to have adjuvant functions via interaction with not only $G$ proteincoupled receptors but also TLR4 ${ }^{73,78}$ On the basis of these studies, 3,5-didodecyloxybenzamidine (TRX, Figure 3) has been selected as a cationic lipid and incorporated into MGlu-HPG-modified liposomes to increase their immune-inducement effects. ${ }^{72}$ The inclusion of TRX into the MGlu-HPG-modified liposomes increases the cellular association of the liposomes and promotes the production of various cytokines (IFN- $\gamma$, IL-10, TNF- $\alpha$, IL-6) from DCs depending on their TRX contents. ${ }^{72}$ Moreover, TRX inclusion has been found to change the intracellular distribution of the liposomes and antigens; the TRX-containing MGlu-HPG-modified liposomes deliver OVA not only to the cytosol but also to the endosome/lysosome. ${ }^{72}$ Positively charged TRX might enhance the association of the negatively charged MGlu-HPG chains on the surface of the liposomal membranes through electrostatic interactions. Therefore, the polymer chains might interact with the liposomal membranes rather than the endosomal membrane, resulting in OVA delivery into the endosomes. This would suggest that the intracellular distributions of OVA in the cytosol, endosomes and lysosomes may be controlled by adjusting the cationic lipid contents in the liposomes. According to the results of the antigen presentation pathway and analysis of antibody production, not only CTL activation but also Th1-polarized immune responses are induced 
a
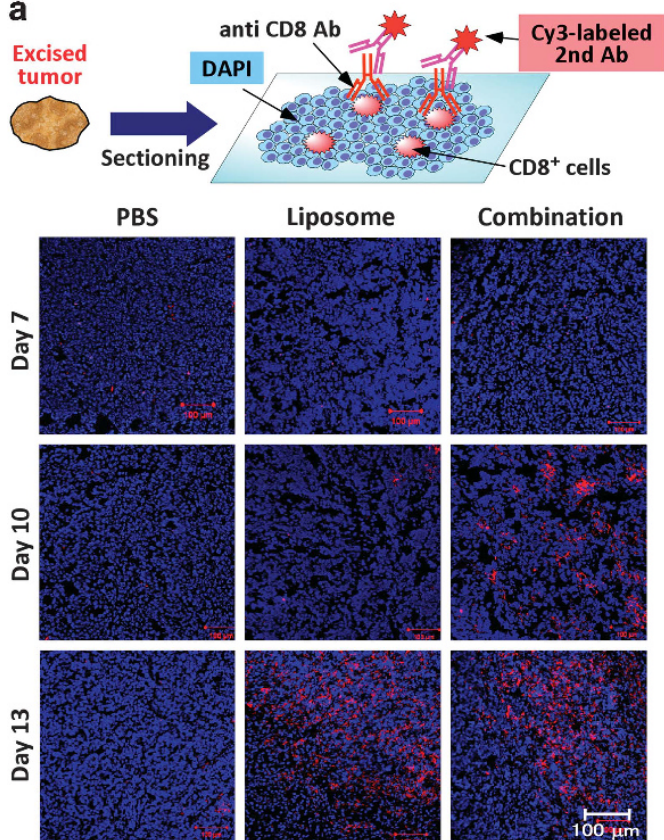

Liposome

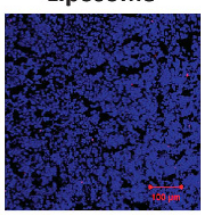

Combination

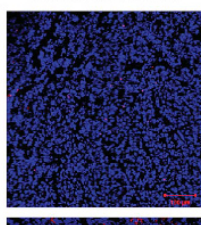

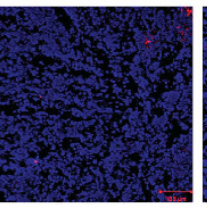
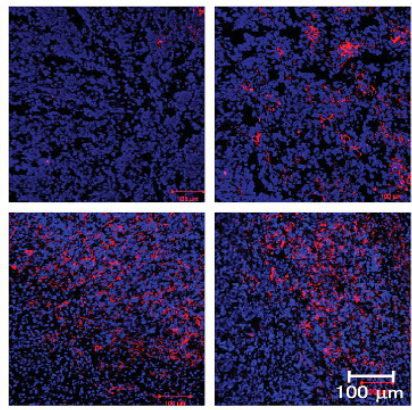

b

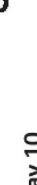

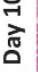
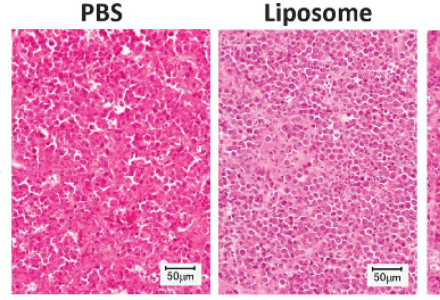

Combination
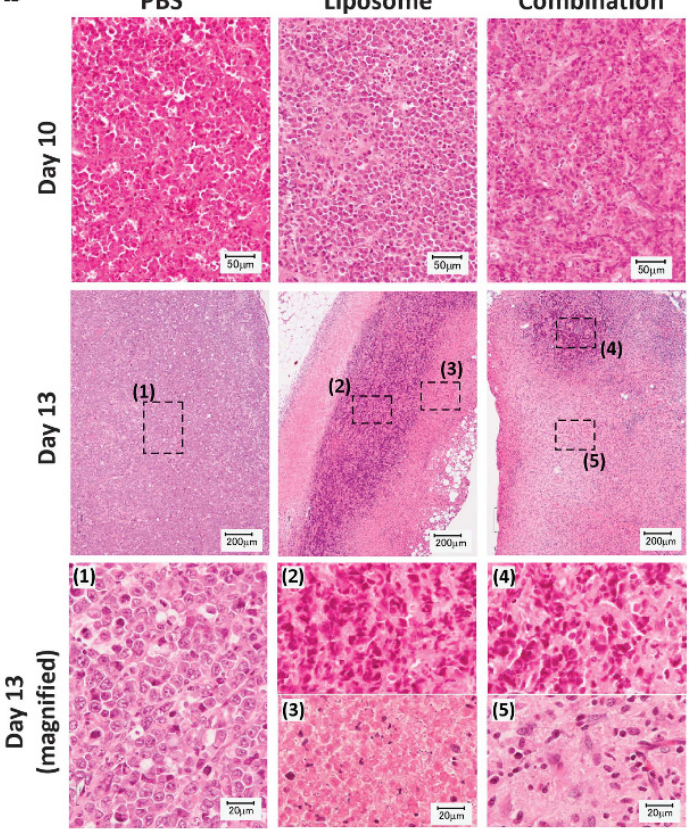

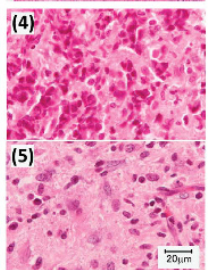

Figure 8 (a) Immunofluorescence analysis of tumor sections from mice subcutaneously administered with phosphate-buffered saline (PBS), OVA-loaded MGluPG-modified liposomes or a combination of OVA-loaded MGluPG-modified liposomes and the IFN- $\gamma$ gene-containing lipoplexes on days 5 and/or 12. CD8-positive cells in the tumor sections were stained using anti-mouse CD8 antibody and Cy3-anti-rat IgG as a secondary antibody (red). Cellular nuclei were stained by DAPI (blue). (b) Hematoxylin and eosin staining for the tumor sections from the mice subcutaneously administered with PBS, OVA-loaded MGluPG-modified liposomes or a combination of OVA-loaded MGluPG-modified liposomes and the IFN- $\gamma$ gene-containing lipoplexes on days 5 and/or 12 . Magnified images for regions (1: normal tumor cells, 2/4: damaged cells with deformed nuclei, 3: denucleated necrotic cells, 5: fibrotic tissues and fibroblast-like cells) of the middle images are shown in the bottom. Partially reproduced from Yuba et al. ${ }^{84}$ with permission. Copyright (2015) Elsevier.

by TRX-containing MGlu-HPG-modified liposomes, which might correspond to the efficient endosome/lysosome delivery of OVA. ${ }^{72}$ Th1 cells support CTL activation through the secretion of Th1 cytokines such as IFN- $\gamma$. Reflecting these results, antitumor effects on tumor-bearing mice have been found to be improved by the inclusion of TRX in the MGlu-HPG-modified liposomes. ${ }^{72}$

It has been demonstrated that Th1 cytokines, such as IFN- $\gamma$, activate cellular immune response efficiently via the promotion of antigen presentation. ${ }^{79}$ Therefore, the combination of cytoplasmic antigen delivery and IFN- $\gamma$ delivery is an attractive strategy for the induction of strong cellular immune responses. However, the half-life of the IFN- $\gamma$ protein administered to the body is too short, and the systemic delivery of IFN- $\gamma$ induces marked side effects. ${ }^{80}$ Therefore, transfection of the IFN- $\gamma$-encoding gene into DCs or tumor cells has been studied instead of the systemic delivery of the IFN- $\gamma$ protein. ${ }^{81-83}$ In our previous work, we have simultaneously delivered the antigenic protein and IFN- $\gamma$ gene as hybrid complexes between liposomes and lipoplexes, which have previously been reported to be efficient nonviral gene carriers for DCs, or as separate administration of liposomes and lipoplexes without pre-mixing. ${ }^{48,84}$ MGluPG-modified liposomes containing OVA have been complexed with TRX-based lipoplexes containing the IFN- $\gamma$ gene via electrostatic interactions. Confocal laser scanning microscopic analysis using fluorescence-labeled complexes has revealed that hybrid complexes deliver both the antigen and gene into the cytosol of DC2.4 cells by fusion with the endosomal membranes derived from the MGluPG-modified liposomes. ${ }^{84}$ Treatment with the hybrid complexes induces IFN- $\gamma$ production in the DC2.4 cells, thus indicating that transfection of the IFN- $\gamma$ gene was transfected into the DC2.4 cells by the hybrid complexes. ${ }^{84}$ In this study, OVA-loaded MGluPG-modified liposomes or hybrid complexes were administered to E.G7-OVA tumor-bearing mice and tumor growth was monitored. Unexpectedly, antitumor effects induced by hybrid complexes were almost identical to those of MGluPG-modified liposome. ${ }^{84}$ Next, OVA-loaded MGluPG-modified liposomes and IFN- $\gamma$ gene-containing lipoplexes were administered without premixing at the same site (combination delivery). In the case of combination delivery, the antitumor effects were enhanced strongly compared with those of the MGluPG-modified liposomes, and all treated mice were completely tumor-free after 60 days. ${ }^{84}$ In comparison, the liposomes and lipoplexes were administered at distant sites in tumor-bearing mice (separate delivery). Separate delivery induced almost identical antitumor effects to those of the liposomes, but less than those obtained with combination delivery, which suggests that the injection of the antigen and the IFN- $\gamma$ gene at the same site is important to obtain their synergetic effects. ${ }^{84}$ Moreover, the induction of CTLs in the spleen was enhanced by combination delivery. ${ }^{84}$ In addition, immunofluorescence staining of the tumor section revealed that the infiltration of CTLs into the tumor tissues at an early stage of the tumor (day 10) was promoted to a greater degree by combination delivery than by the MGluPG-modified liposomes (Figure $8 \mathrm{a}$ ) ${ }^{84}$ According to the results of the hematoxylin and eosin stain of the tumor sections, more tumor cells were killed at the early stage by combination delivery than by the liposomes (Figure $8 \mathrm{~b}$ ). These results indicate that combination delivery of the antigen and IFN- $\gamma$ gene is an effective strategy for the enhancement of antitumor immunity.

\section{SUMMARY AND OUTLOOK}

In this review, $\mathrm{pH}$-sensitive polymer-based antigen delivery systems for the induction of antigen-specific immune responses have been overviewed. The $\mathrm{pH}$-sensitive polymer structures strongly affect their 
$\mathrm{pH}$-sensitivity, cellular association, intracellular delivery performance, properties of DC activation and in vivo immune-inducing functions. Highly hydrophobic side chain structures are suitable for the efficient intracellular delivery of antigens and for the induction of antitumor immunity. Dextran-based $\mathrm{pH}$-sensitive polymers have also been developed as safer functional polymers. For the dextran-based polymers, the content of the $\mathrm{pH}$-sensitive units in the polymer strongly affect their properties of the antigen delivery and the induction of antitumor immunity. Therefore, not only the side-chain structure but also their content in the polymer chains should be optimized further to obtain more effective $\mathrm{pH}$-sensitive polymer-based antigen carriers. The inclusion of cationic lipids into $\mathrm{pH}$-sensitive polymer-modified liposomes has promoted their immune-inducing effects considerably. Not only cationic lipids but also various adjuvant molecules, such as TLR ligands, can be incorporated into the liposomes. Specific combinations of TLR ligands are known to induce synergetic immune-activating effects. ${ }^{85,86}$ Therefore, the inclusion of multiple TLR ligands into cationic lipid-containing liposomes might generate highly potent antigen delivery systems. Notably, the combination of the cytokine gene delivery system (lipoplexes) and liposomes can completely cure tumor-bearing mice. The combination of other cytokine or chemokine genes, such as IL-12, TGF- $\beta$ or CCR7, might create various immune-inducing systems or immunosuppressioncanceling systems in tumor microenvironments.

Our recent and current studies have used a model antigen (chicken egg albumin, OVA), which has strong immunogenicity against mice, for the evaluation of the immune responses of $\mathrm{pH}$-sensitive polymermodified liposomes. For a more practical evaluation, we have started the use of human cancer antigenic peptides, such as glypican-3 (GPC3)-derived peptide, which is overexpressed in hepatocellular carcinomas, and insulin-like growth factor II mRNA-binding protein 3 (IMP-3)-derived peptide, which is overexpressed in cases of head-andneck malignant tumors, lung cancer and esophageal cancer, for the evaluation of $\mathrm{pH}$-sensitive polymer-modified liposomes. ${ }^{87,88} \mathrm{CHexPG}$ $\mathrm{PE}$ liposomes containing any of the respective peptides induce much more efficient cross-presentation than free peptide solutions in human autologous DCs. ${ }^{87,88}$ These latest studies have clearly indicated that our $\mathrm{pH}$-sensitive polymer-modified liposomes present the potential for immune-inducing functions, not only for model antigenic proteins but also for clinically used cancer antigenic peptides. We believe that the further optimization of the $\mathrm{pH}$-sensitive polymer structures, adjuvant molecule inclusion and the combination of cytokine gene delivery systems on $\mathrm{pH}$-sensitive polymer-modified liposomes will provide improved antigen delivery systems for practical use in cancer immunotherapy.

\section{CONFLICT OF INTEREST}

The author declares no conflict of interest.

\section{ACKNOWLEDGEMENTS}

This work was supported by Grants-in-aid for Scientific Research from the Ministry of Education, Science, Sports, and Culture in Japan (15H03024, 25750177,23700563 and 22800055). I am grateful to all my coworkers and our students for their contributions. Especially, I express special appreciation to Professor Kenji Kono (Osaka Prefecture University) for his kind support and encouragement.

1 Restifo, N. P., Dudley, M. E. \& Rosenberg, S. A. Adoptive immunotherapy for cancer: harnessing the T cell response. Nat. Rev. Immunol. 12, 269-281 (2012).
2 Mellman, I., Coukos, G. \& Dranoff, G. Cancer immunotherapy comes of age. Nature 480, 480-489 (2011).

3 Vanneman, M. \& Dranoff, G. Combining immunotherapy and targeted therapies in cancer treatment. Nat. Rev. Cancer 12, 237-251 (2012).

4 Banchereau, J. \& Palucka, A. K. Dendritic cells as therapeutic vaccines against cancer. Nat. Rev. Immunol. 5, 296-306 (2005).

5 Higano, C., Small, E., Schellhammer, P., Yasothan, U., Gubernick, S., Kirkpatrick, P. \& Kantoff, P. Sipuleucel-T. Nat. Rev. Drug Discov. 9, 513-514 (2010).

6 Kantoff, P., Higano, C., Shore, N., Berger, E., Small, E., Penson, D., Redfern, C. H., Ferrari, A. C., Dreicer, R., Sims, R. B., Xu, Y., Frohlich, M. W. \& Schellhammer, P. F. Sipuleucel-T immunotherapy for castration-resistant prostate cancer. N. Engl. J. Med. 363, 411-422 (2010).

7 Wolchok, J. D. \& Chan, T. A. Antitumor immunity get a boost. Nature 515 496-498 (2014).

8 Banchereau, J. \& Steinman, R. M. Dendritic cells and the control of immunity. Nature 392, 245-252 (1998).

9 Mellman, I. \& Steinman, R. M. Dendritic cells: specialized and regulated antigen processing machines. Cell 106, 255-258 (2001).

10 Nakanishi, T., Hayashi, A., Kunisawa, J., Tsutsumi, Y., Tanaka, K., Yashiro-Ohtani, Y. Nakanishi, M., Fujiwara, H., Hamaoka, T. \& Mayumi, T. Fusogenic liposomes efficiently deliver exogenous antigen through the cytoplasm into the MHC class I processing pathway. Eur. J. Immunol. 30, 1740-1747 (2000).

11 Kunisawa, J., Nakanishi, T., Takahashi, I., Okudaira, A., Tsutsumi, Y., Katayama, K. Nakagawa, S., Kiyono, H. \& Mayumi, T. Sendai virus fusion protein mediates simultaneous induction of MHC class I/II-dependent mucosal and systemic immune responses via the nasopharyngeal-associated lymphoreticular tissue immune system. J. Immunol. 167, 1406-1412 (2001).

12 Bungener, L., Serre, K., Bijl, L., Leserman, L., Wilschut, J., Daemen, T. \& Machy, P. Virosome-mediated delivery of protein antigens to dendritic cells. Vaccine 20 , 2287-2295 (2002).

13 Bungener, L., Huckriede, A., de Mare, A., de Vries-Idema, J., Wilschut, J. \& Daemen, T. Virosome-mediated delivery of protein antigens in vivo: efficient induction of class I MHC-restricted cytotoxic T Iymphocyte activity. Vaccine 23, 1232-1241 (2005).

14 Panyam, J., Zhou, W. Z., Prabha, S., Sahoo, S. K. \& Labhasetwar, V. Rapid endo-lysosomal escape of poly(DL-lactide-co-glycolide) nanoparticles: implications for drug and gene delivery. FASEB J 16, 1217-1226 (2002).

$15 \mathrm{Ma}$, W., Chen, M., Kaushal, S., McElroy, M., Zhang, Y., Ozkan, C., Bouvet, M., Kruse, C., Grotjahn, D., Ichim, T. \& Minev, B. PLGA nanoparticle-mediated delivery of tumor antigenic peptides elicits effective immune responses. Int. J. Nanomedicine 7 , 1475-1487 (2012).

16 Shima, F., Akagi, T., Uto, T. \& Akashi, M. Manipulating the antigen-specific immune response by the hydrophobicity of amphiphilic poly $(\gamma$-glutamic acid) nanoparticles. Biomaterials 34, 9709-9716 (2013).

17 Uto, T., Wang, X., Akagi, T., Zenkyu, R., Akashi, M. \& Baba, M. Improvement of adaptive immunity by antigen-carrying biodegradable nanoparticles. Biochem. Biophys. Res. Commun. 379, 600-604 (2009).

18 Akagi, T., Baba, M. \& Akashi, M. Biodegradable nanoparticles as vaccine adjuvants and delivery systems: regulation of immune responses by nanoparticle-based vaccine. Adv. Polym. Sci. 247, 31-64 (2012)

19 Akagi, T., Zhu, Y., Shima, F. \& Akashi, M. Biodegradable nanoparticles composed of enantiomeric poly $(\gamma$-glutamic acid)-graft-poly(lactide) copolymers as vaccine carriers for dominant induction of cellular immunity. Biomater. Sci. 2, 530-537 (2014).

20 Bachelder, E. M., Beaudette, T. T., Broaders, K. E., Fréchet, J. M. J., Albrecht, M. T., Mateczun, A. J., Ainslie, K. M., Pesce, J. T. \& Keane-Myers, A. M. In vitro analysis of acetalated dextran microparticles as a potent delivery platform for vaccine adjuvants. Mol. Pharm. 7, 826-835 (2010).

21 Cui, L., Cohen, J. A., Broaders, K. E., Beaudette, T. T. \& Fréchet, J. M. J. Mannosylated dextran nanoparticles: a pH-sensitive system engineered for immunomodulation through mannose targeting. Bioconj. Chem. 22, 949-957 (2011).

22 Li, P., Luo, Z., Liu, P., Gao, N., Zhang, Y., Pan, H., Liu, L., Wang, C., Cai, L. \& Ma, Y. Bioreducible alginate-poly(ethylenimine) nanogels as an antigen-delivery system robustly enhance vaccine-elicited humoral and cellular immune responses. J. Control. Release 168, 271-279 (2013).

23 Zhou, F. \& Huang, L. Liposome-mediated cytoplasmic delivery of proteins: an effective means of accessing the MHC class I-restricted antigen presentation pathway. Immunomethods 4, 229-235 (1994).

24 Reddy, R., Zhou, F., Huang, L., Carbone, F., Bevan, M. \& Rouse, T. B. $\mathrm{pH}$-sensitive liposomes provide an efficient means of sensitizing target cells to class restricted CTL recognition of a soluble protein. J. Immun. Methods 141 157-163 (1991).

25 Tachibana, R., Harashima, H., Shono, M., Azumano, M., Niwa, M., Futaki, S. \& Kiwada, $\mathrm{H}$. Intracellular regulation of macromolecules using $\mathrm{pH}$-sensitive liposomes and nuclear localization signal: qualitative and quantitative evaluation of intracellular trafficking. Biochem. Biophys. Res. Commun. 251, 538-544 (1998).

26 Nakamura, T., Moriguchi, R., Kogure, K., Shastri, N. \& Harashima, H. Efficient MHC class I presentation by controlled intracellular trafficking of antigens in octaargininemodified liposomes. Mol. Ther. 16, 1507-1514 (2008).

27 Suzuki, R., Oda, Y., Utoguchi, N., Namai, E., Taira, Y., Okada, N., Kadowaki, N., Kodama, T., Tachibana, K. \& Maruyama, K. A novel strategy utilizing ultrasound for antigen delivery in dendritic cell-based cancer immunotherapy. J. Control. Release 133, 198-205 (2009). 
28 Huckriede, A., Bungener, L., Stegmann, T., Daemen, T., Medema, J., Palache, A. M. \& Wilschut, J. The virosome concept for influenza vaccines. Vaccine 23S1, S1/26-S1/38 (2005).

29 Torchilin, V. P. Recent advances with liposomes as pharmaceutical carriers. Nat. Rev. Drug. Discov. 4, 145-160 (2005).

30 Fujiwara, M., Grubbs, R. H. \& Baldeschwieler, J. D. Characterization of pH-dependent poly(acrylic acid) complexation with phospholipid vesicles. J. Colloid. Interface Sci. 185, 210-216 (1997)

31 Seki, K. \& Tirrell, D. A. pH-Dependent complexation of poly(acrylic acid) derivatives with phospholipid vesicle membrane. Macromolecules 17, 1692-1698 (1984).

32 Tirrell, D. A., Takigawa, D. \& Seki, K. pH Sensitization of phospholipid vesicles via complexation with synthetic poly(carboxylic acid)s. Ann. NY Acad. Sci. 446, 237-248 (1985)

33 Borden, K., Eum, K., Langley, K., Tan, J., Tirrell, D. A. \& Voycheck, C. pH-dependent vesicle-to-micelle transition in an aqueous mixture of dipalmitoylphosphatidylcholine and a hydrophobic polyelectrolyte. Macromolecules 21, 2649-2651 (1988).

34 Thomas, J. L. \& Tirrell, D. A. Polyelectrolyte-sensitized phospholipid vesicles. Acc. Chem. Res. 25, 336-342 (1992)

35 Maeda, M., Kumano, A. \& Tirrell, D. A. $\mathrm{H}^{+}$-Induced release of contents of phosphatidylcholine vesicles bearing surface-bound polyelectrolyte chains. J. Am. Chem. Soc. 110, 7455-7459 (1988).

36 Kusonwiriyawong, C., van de Wetering, P., Hubbell, J. A., Merkle, H. P. \& Walter, E. Evaluation of $\mathrm{pH}$-dependent membrane-disruptive properties of poly(acrylic acid) derived polymers. Eur. J. Pharm. Biopharm. 56, 237-246 (2003).

37 Murthy, N., Robichaud, J. R., Tirrell, D. A., Stayton, P. S. \& Hoffman, A. S. The design and synthesis of polymers for eukaryotic membrane disruption. J. Control. Release 61, 137-143 (1999).

38 Flanary, S., Hoffman, A. S. \& Stayton, P. S. Antigen delivery with poly(propylacrylic acid) conjugation enhances MHC-1 presentation and T-cell activation. Bioconj. Chem. 20, 241-248 (2009).

39 Foster, S., Duvall, C. L., Crownover, E. F., Hoffman, A. S. \& Stayton, P. S. Intracellular delivery of a protein antigen with an endosomal-releasing polymer enhances CD8 T-cell production and prophylactic vaccine efficacy. Bioconj. Chem. 21, 2205-2212 (2010).

40 Keller, S., Wilson, J. T., Patilea, G. I., Kern, H. B., Convertine, A. J. \& Stayton, P. S. Neutral polymer micelle carriers with $\mathrm{pH}$-responsive, endosome-releasing activity modulate antigen trafficking to enhance $\mathrm{CD} 8(+) \mathrm{T}$ cell responses. J. Control. Release 191, 24-33 (2014)

41 Wilson, J. T., Keller, S., Manganiello, M. J., Cheng, C., Lee, C.-C., Opara, C., Convertine, A. \& Stayton, P. S. pH-Responsive nanoparticle vaccines for dual-delivery of antigens and immunostimulatory oligonucleotides. ACS Nano 7, 3912-3925 (2013).

42 Kono, K., Zenitani, K. \& Takagishi, T. Novel pH-sensitive liposomes: liposomes bearing a poly(ethylene glycol) derivative with carboxyl groups. Biochim. Biophys. Acta. 1193, 1-9 (1994)

43 Kono, K., Igawa, T. \& Takagishi, T. Cytoplasmic delivery of calcein mediated by liposomes modified with a $\mathrm{pH}$-sensitive poly(ethylene glycol) derivative. Biochim. Biophys. Acta. 1325, 143-154 (1997).

44 Sakaguchi, N., Kojima, C., Harada, A. \& Kono, K. Preparation of pH-sensitive poly (glycidol) derivatives with varying hydrophobicities: their ability to sensitize stable liposomes to pH. Bioconj. Chem. 19, 1040-1048 (2008).

45 Yuba, E., Kojima, C., Harada, A., Tana, Watarai, S. \& Kono, K. pH-Sensitive fusogenic polymer-modified liposomes as a carrier of antigenic proteins for activation of cellular immunity. Biomaterials 31, 943-951 (2010).

46 Albert, M. L., Pearce, S. F., Francisco, L. M, Sauter, B., Roy, P., Silverstein, R. L. \& Bhardwaj, N. Immature dendritic cells phagocytose apoptotic cells via $\alpha_{v} \beta_{5}$ and CD36, and cross-present antigens to cytotoxic T lymphocytes. J. Exp. Med. 188, 1359-1368 (1998)

47 Platt, N. \& Gordon, S. Scavenger receptors: diverse activities and promiscuous binding of polyanionic ligands. Chem. Biol. 5, R193-R203 (1998).

48 Yuba, E., Kojima, C., Sakaguchi, N., Harada, A., Koiwai, K. \& Kono, K. Gene delivery to dendritic cells mediated by complexes of lipoplexes and $\mathrm{pH}$-sensitive fusogenic polymer-modified liposomes. J. Control. Release 130, 77-83 (2008).

49 Miller, C. R., Bondurant, B., McLean, S. D., McGovern, K. A. \& O'Brien, D. F Liposome-cell interactions in vitro: effect of liposome surface charge on the binding and endocytosis of conventional and sterically stabilized liposomes. Biochemistry 37, 12875-12883 (1998).

50 Yue, Z.-G., Wei, W., Lv, P.-P., Yue, H., Wang, L.-Y., Su, Z.-G. \& Ma, G. H. Surface charge affects cellular uptake and intracellular trafficking of chitosan-based nanoparticles. Biomacromolecules 12, 2440-2446 (2011).

51 Bullough, P. A., Hughson, F. M., Skehel, J. J. \& Wiley, D. C. Structure of influenza haemagglutinin at the $\mathrm{pH}$ of membrane fusion. Nature 371, 37-43 (1994).

52 Hamilton, B. S., Whittaker, G. R. \& Daniel, S. Influenza virus-mediated membrane fusion: determinants of hemagglutinin fusogenic activity and experimental approaches for assessing virus fusion. Viruses 4, 1144-1168 (2012).

53 Yuba, E., Harada, A., Sakanishi, Y. \& Kono, K. Carboxylated hyperbranched poly (glycidol)s for preparation of $\mathrm{pH}$-sensitive liposomes. J. Control. Release 149, 72-80 (2011)

54 Yuba, E., Kono, Y., Harada, A., Yokoyama, S., Arai, M., Kubo, K. \& Kono, K. The application of $\mathrm{pH}$-sensitive polymer-lipids to antigen delivery for cancer immunotherapy. Biomaterials 34, 5711-5721 (2013).

55 Harding, C. V. \& Song, R. Phagocytic processing of exogenous particulate antigens by macrophages for presentation by class I MHC molecules. J. Immunol. 153, 4925-4933 (1994).
56 Li, Y., Ke, Y., Gottlieb, P. D. \& Kapp, J. A. Delivery of exogenous antigen into the major histocompatibility complex class I and class II pathways by electroporation. J. Leukoc. Biol. 56, 616-624 (1994).

57 Mata-Haro, V., Cekic, C., Martin, M., Chilton, P. M., Casella, C. R. \& Mitchel, T. C. The vaccine adjuvant monophosphoryl lipid $A$ as a TRIF-biased agonist of TLR4. Science 316, 1628-1632 (2007).

58 Yuba, E., Harada, A., Sakanishi, Y., Watarai, S. \& Kono, K. A liposome-based antigen delivery system using $\mathrm{pH}$-sensitive fusogenic polymers for cancer immunotherapy. Biomaterials 34, 3042-3052 (2013).

59 Hebishima, T., Yuba, E., Kono, K., Takeshima, S., Ito, Y. \& Aida, Y. pH-sensitive fusogenic 3-methyl-glutarylated hyperbranched poly(glycidol) (MGlu-HPG)-conjugated liposome induces antigen-specific cellular and humoral immunity. Clin. Vaccine Immunol. 19, 1492-1498 (2012).

60 Watarai, S., Iwase, T., Tajima, T., Yuba, E. \& Kono, K. Efficiency of pH-sensitive fusogenic polymer-modified liposomes as a vaccine carrier. Scientific World J. 2013, 903234 (2013).

61 Watarai, S., Iwase, T., Tajima, T., Yuba, E., Kono, K. \& Sekiya, Y. Application of $\mathrm{pH}$-sensitive fusogenic polymer-modified liposomes for development of mucosal vaccines. Vet. Immunol. Immunopathol. 158, 62-72 (2014).

62 Beachey, E. H. Bacterial adherence: adhesin-receptor interactions mediating the attachment of bacteria to mucosal surfaces. J. Infect. Dis. 143, 325-345 (1981).

63 Edwards, R. A. \& Puente, J. L. Fimbrial expression in enteric bacteria: acritical step in intestinal pathogenesis. Trends Microbiol. 7, 282-287 (1998).

64 Khan, A. S., Muhldorfer, I., Demuth, V., Wallner, U., Korhonen, T. K. \& Hacker, J. Functional analysis of the minor subunits of $S$ fimbrial adhesions (Sfal) in pathogenic Escherichia coli. Mol. Gen. Genet. 263, 4223-4243 (2000).

65 Klemm, P. \& Schembri, M. K. Bacterial adhesin: function and structure. Int. J. Med. Microbiol. 290, 27-35 (2000).

66 Bouvet, J. P. \& Fischetti, V. A. Diversity of antibody-mediated immunity at the mucosal barrier. Infect. Immun. 67, 2687-2691 (1999).

67 Yuba, E. Antigen delivery using $\mathrm{pH}$-sensitive polymer-modified liposomes and their application to cancer immunotherapy. Major Histocompatibility Complex 20, 181-189 (2013).

68 Yuba, E., Tajima, N., Yoshizaki, Y., Harada, A., Hayashi, H. \& Kono, K. Dextran derivative-based $\mathrm{pH}$-sensitive liposomes for cancer immunotherapy. Biomaterials $\mathbf{3 5}$, 3091-3101 (2014).

69 Alving, C. R., Rao, M., Steers, N. J., Matyas, G. R. \& Mayorov, A. V. Liposomes containing lipid $A$ : an effective, safe, generic adjuvant system for synthetic vaccines. Expert Rev. Vaccines 11, 733-744 (2012).

70 Morelli, A. E., Zahorchak, A. F., Larregina, A. T., Colvin, B. L., Logar, A. J., Takayama, T., Falo, L. D. \& Thomson, A. W. Cytokine production by mouse myeloid dendritic cells in relation to differentiation and terminal maturation induced by lipopolysaccharide or CD40 ligation. Blood 98, 1512-1523 (2001).

71 Weeratna, R. D., McCluskie, M. J., Xu, Y. \& Davis, H. L. CpG DNA induces stronger immune responses with less toxicity than other adjuvants. Vaccine 18, 1755-1762 (2000).

72 Yoshizaki, Y., Yuba, E., Sakaguchi, N., Koiwai, K., Harada, A. \& Kono, K. Potentiation of $\mathrm{pH}$-sensitive polymer-modified liposomes with cationic lipid inclusion as antigen delivery carriers for cancer immunotherapy. Biomaterials 35, 8186-8196 (2014).

73 Lonez, C., Vandenbranden, M. \& Ruysschaert, J. M. Cationic lipids activate intracellular signaling pathways. Adv. Drug Deliv. Rev. 64, 1749-1758 (2012).

74 Chen, W., Yan, W. \& Huang, L. A simple but effective cancer vaccine consisting of an antigen and a cationic lipid. Cancer Immunol. Immunother. 57, 517-530 (2008).

75 Vasievich, E. A., Chen, W. \& Huang, L. Enantiospecific adjuvant activity of cationic lipid DOTAP in cancer vaccine. Cancer Immunol. Immunother. 60, 629-638 (2011).

76 Vasievich, E. A., Ramishetti, S., Zhang, Y. \& Huang, L. Trp2 peptide vaccine adjuvanted with (R)-DOTAP inhibits tumor growth in an advanced melanoma model. Mol. Pharm. $\mathbf{9}$, 261-268 (2012).

77 Yan, W., Chen, W. \& Huang, L. Reactive oxygen species play a central role in the activity of cationic liposome based cancer vaccine. J. Control. Release 130, 22-28 (2008).

78 Tanaka, T., Legat, A., Adam, E., Steuve, J., Gatot, J. S., Vandenbranden, M., Ulianov, L., Lonez, C., Ruysschaert, J. M., Muraille, E., Tuynder, M., Goldman, M. \& Jacquet, A. DiC14-amidine cationic liposomes stimulate myeloid dendritic cells through Toll like receptor 4. Eur. J. Immunol. 38, 1351-1357 (2008).

79 Fong, L. \& Engleman, E. G. Dendritic cells in cancer immunotherapy. Annu. Rev. Immunol. 18, 245-273 (2000).

80 Wu, J., Xiao, X., Jia, H., Chen, J., Zhu, Y., Zhao, P., Lin, H. \& Huang, W. Dynamic distribution and expression in vivo of the human interferon gamma gene delivered by adenoviral vector. BMC Cancer 9, 55 (2009).

81 Shiloni, E., Karp, S. E., Custer, M. C., Shilyansky, J., Restifo, N. P., Rosenberg, S. A. \& Mulé, J. J. Retroviral transduction of interferon- $\gamma$ cDNA into a nonimmunogenic murinefibrosarcoma: generation of T cells in draining lymph nodes capable of treating established parental metastatic tumor. Cancer Immunol. Immunother. 37, 286-292 (1993)

82 Kobayashi, N., Kuramoto, T., Chen, S., Watanabe, Y. \& Takakura, Y. Therapeutic effect of intravenous interferon gene delivery with naked plasmid DNA in murine metastasis models. Mol. Ther. 6, 737-744 (2002).

83 Wijesekera, D. P. H., Sugiura, K., Yuba, E., Ueda, K., Wijewardana, V., Kanegi, R., Nishimura, T., Ushigusa, T., Hatoya, S., Kono, K. \& Inaba, T. Enhancement of antitumor immune responses by transfection of IFN $\gamma$ gene into tumor using a novel type synthetic vector. Vet. Immunol. Immunopathol. 162, 59-64 (2014).

84 Yuba, E., Kanda, Y., Yoshizaki, Y., Teranishi, R., Harada, A., Sugiura, K., Izawa, T., Yamate, J, Sakaguchi, N . Koiwai, K. \& Kono, K. pH-Sensitive polymer-liposome-based 
antigen delivery systems potentiated with interferon- $\gamma$ gene lipoplex for efficient cancer immunotherapy. Biomaterials 67, 214-224 (2015).

85 Zhu, Q., Egelston, C., Gagnon, S., Sui, Y., Belyakov, I. M., Klinman, D. M. \& Berzofsky, J. A. Using 3 TLR ligands as a combination adjuvant induces qualitative changes in T cell responses needed for antiviral protection in mice. J. Clin. Invest. 120, 607-616 (2010).

86 Warger, T., Osterloh, P., Rechtsteiner, G., Fassbender, M., Heib, V., Schmid, B., Schmitt, E., Schild, H. \& Radsak, M. P. Synergistic activation of dendritic cells by combined Toll-like receptor ligation induces superior CTL responses in vivo. Blood 15, 544-550 (2006).
87 Sayem, M. A., Tomita, Y., Yuno, A., Hirayama, M., Irie, A., Tsukamoto, H., Senju, S., Yuba, E., Yoshikawa, T., Kono, K., Nakatsura, T. \& Nishimura, Y. Identification of glypican-3-derived long peptides activating both CD8+ and CD4+ T-cells; prolonged overall survival in cancer patients with Th cell response. Oncolmmunology 5, e1062209 (2016).

88 Hirayama, M., Tomita, Y., Yuno, A., Tsukamoto, H., Senju, S., Imamura, Y., Sayem, M. A., Irie, A., Yoshitake, Y., Fukuma, D., Shinohara, M., Hamada, A., Jono, H., Yuba, E., Kono, K., Yoshida, K., Tsunoda, T., Nakayama, H. \& Nishimura, Y. An oncofetal antigen, IMP-3-derived long peptides induce immune responses of both helper T cells and CTLs. Oncolmmunology 5, e1123368 (2016).

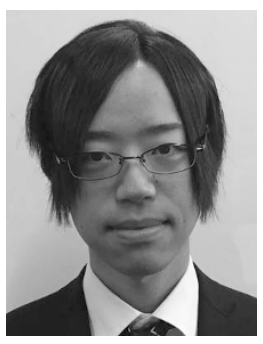

Dr Eiji Yuba was born in Nara Prefecture, Japan in 1983. He received his B.S. degree in 2006 and his PhD degree of engineering in 2010 under the supervision of Professor Kenji Kono from Osaka Prefecture University. He received research fellowship for young scientist in JSPS (DC2, 2009-2010) and has been an assistant professor of the research group of Professor Kenji Kono in Department of Applied Chemistry, Graduate School of Engineering, Osaka Prefecture University since 2010. He was a recipient of the Award for Encouragement of Research in Polymer Science from The Society of Polymer Science, Japan (2015), Biomacromolecules Best Poster Awards in 3rd Symposium on Innovative Polymers for Controlled Delivery (SIPCD2014) and several other awards. His main research interest relates to functional polymer-modified liposomes and their application to gene, protein, and peptide delivery to establish efficient antigen delivery system for cancer immunotherapy. 